\title{
Detection of aortic dissection by transoesophageal echocardiography
}

\author{
R ERBEL, N BÖRNER, D STELLER, J BRUNIER, ^ M THELEN, * C PFEIFFER, \\ $S$ MOHR-KAHALY, S IVERSEN, $\dagger$ H OELERT, $\dagger$ J MEYER \\ From the Second Medical Clinic, *Department of Radiology, and $\dagger$ Department of Cardiovascular Surgery, \\ Johannes Gutenberg University, Mainz, Federal Republic of Germany
}

SUMMARY The diagnostic value of a combination of transoesophageal and transthoracic echocardiography was evaluated in 21 patients with dissection of the aorta. The results were compared with those of computed tomography, aortography, and with findings at operation or necropsy or both. Transthoracic echocardiography identified three of the four patients with type I dissection, two of the five patients with type II dissection, and one of the 12 patients with type III dissection. When transoesophageal echocardiography was used as well the degree of aortic dissection was identified correctly in all 21 patients. In one patient with type I and in eight patients with type III dissection spontaneous echocardiographic contrast with a mural thrombus within the false lumen could be detected. Computed tomography was unable to demonstrate an intimal flap in one of two patients studied with type I dissection, in two of three patients with type II dissection, and in one of nine patients with type III dissection. Aortography was negative in one of two patients studied with type I dissection, two of four patients with type II dissection, and in one of eight patients with type III dissection.

The whole thoracic aorta can be imaged by a combination of transthoracic and transoesophageal echocardiography. The addition of transoesophageal echocardiography to transthoracic echocardiography improves the recognition of aortic dissection. Furthermore, this examination can be performed at the bedside and the findings can be used as a basis for treatment.

Echocardiography is a useful method for detecting zortic dissection. ${ }^{1-4}$ The aortic arch can be imaged irom the suprasternal approach. ${ }^{56}$ The descending part of the thoracic aorta can be imaged behind the heart in the left parasternal view. ${ }^{78}$ Thus almost the whole thoracic aorta can be visualised; however, there are difficulties in imaging the dissections in the distal part of the aorta. The whole aorta can be imaged in only about $70 \%$ of obese patients and those with pulmonary emphysema. ${ }^{4}$ Cross sectional transoesophageal echocardiography, introduced by Hanrath et al, ${ }^{9}$ has opened-up a new approach- to both the heart ${ }^{10-12}$ and the aorta ${ }^{13}$ making it possible to produce cross sectional images of the descending aorta in multiple scanning planes. ${ }^{13}$

Requests for reprints to Dr R Erbel, II Medical Clinic, Johannes Gutenberg University, Langenbeckstrasse 1, D-6500 Mainz, Federal Republic of Germany.

Accepted for publication 5 January 1987
We have evaluated the accuracy of transoesophageal cross sectional echocardiography for the diagnosis of aortic dissection and we have compared its effectiveness with transthoracic echocardiography, computed tomography, and aortography.

\section{Patients and methods}

The ascending aorta was imaged by transthoracic echocardiography in the long and short axes in different planes from the precordial, apicat, supiasternal, and subcostal approaches. ${ }^{5-8}$ Over a 36 month period 13700 transthoracic echocardiograms were obtained. Of these patients, 800 were also examined by transoesophageal echocardiography because disease of the left and right atria and mitral and aortic values was suspected. Aortic dissection was detected by transoesophageal echocardiography in 21 patients. These patients, in whom the aortic 
dissection was also shown by alternative techniques, form the basis of the study. In $25(3 \%)$ of the 800 patients transoesophageal echocardiography was not possible because the patient could not tolerate the gastroscopic procedure. Side effects were seen in two patients. One suffered from a severe attack of asthma and one showed a transient grade III atrioventricular block during introduction of the echoscope. When necessary patients were given intravenous atropine $(0.5 \mathrm{mg})$ before the procedure. All patients gave their informed consent and fasted for at least four hours before the procedure. Each patient's history was studied carefully to exclude a diverticulum of the oesophagus. All echocardiographic examinations were performed with a V-3400 R or CV 60 (Diasonics, Palo Alto) phased array sector scanner. A $2 \cdot 25 \mathrm{MHz}$ transducer was used for the transthoracic studies. Transoesophageal echocardiography was performed with a $3.5 \mathrm{MHz}$ transducer array of 48 elements fitted to the distal end of a conventional $12 \mathrm{~mm}$ endoscope. ${ }^{9}$ Echocardiographic readings were stored on a video tape recorder.

The echoscope was introduced into the oesophagus up to $40 \mathrm{~cm}$ distal to the patient's teeth. When the transducer was directed anteriorly the aortic valve and aortic root could be imaged as previously described. ${ }^{9}$ More distal parts of the ascending aorta and aortic arch could not be imaged from this point except in patients with aortic ectasia.

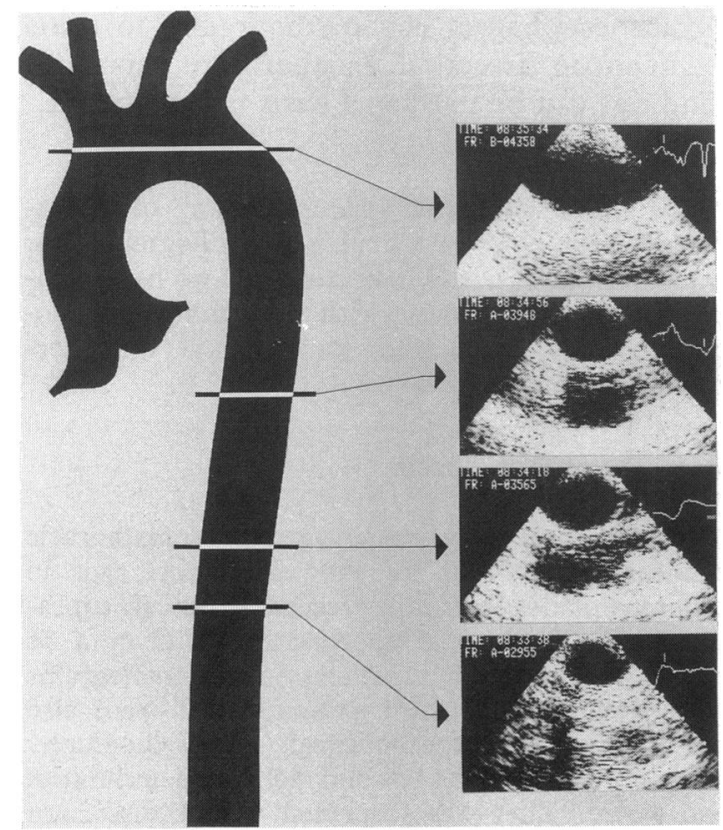

Fig 1 Transoesophageal echocardiographic images of the thoracic aorta in a normal subject.

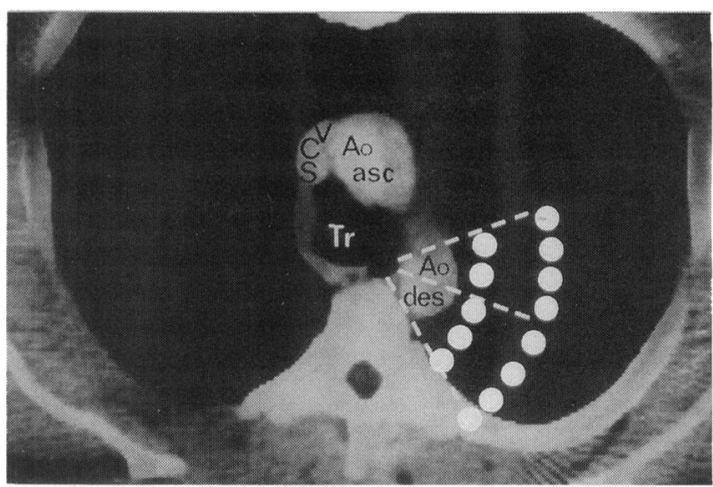

Fig 2 Computed tomographic image showing the sector scan for transoesophageal echocardiogram imaging of the descending aorta. VCS, superior vena cava; Tr, trachea; Ao des, descending aorta; Ao asc, ascending aorta.

By rotating the transducer posteriorly, the descending part of the thoracic aorta was visualised (fig 1). The sector scans from the echoscope are shown on a computed tomogram at the descending aorta (fig 2). By moving the echoscope within the oesophagus multiple cross sectional images could be obtained (fig 2). At a depth of $20-22 \mathrm{~cm}$ the descending aortic arch could be visualised (fig 3 ). Normal values for the aortic diameter were determined in 12 controls. Mean (SD) values are given.

Aortography (Cardioscop U, Siemens) and computed tomographic studies (scan time $4 \mathrm{~s}$; Somatom, Siemens) were also performed so that the accuracy of transoesophageal echocardiography could be compared with standard methods.

Echocardiographically and angiographically an aneurysm was defined as a localised dilatation of a portion of the thoracic aorta. Diagnosis of a dis-

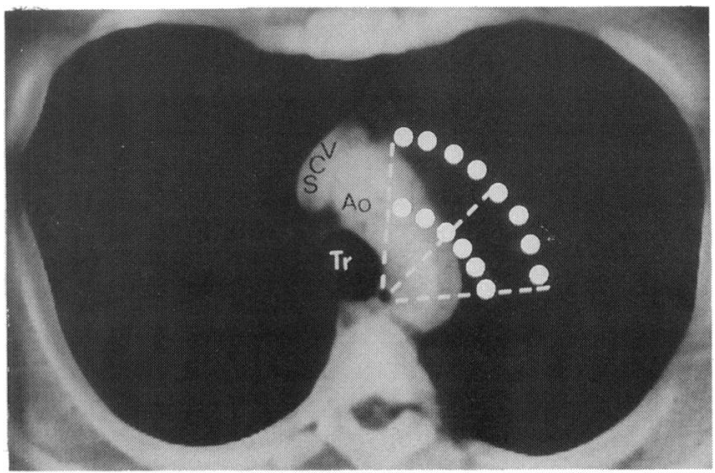

Fig 3 Computed tomogram showing the sector scan for transoesophageal echocardiogram imaging of the aortic arch. Because of the interposition trachea ( $T r$ ) the ascending aorta cannot be imaged from this point. Ao, aorta; VCS, superior vena cava. 
section was based on the recognition of an intimal tear, identified as a linear structure that changed position during the cardiac cycle. A dissection was detected in 21 patients. The extent of the dissection was defined according to the DeBakey classification ${ }^{14}$ : type I dissection begins in the ascending aorta and extends beyond the arch, type II dissection is confined to the ascending aorta, and type III dissection originates in the descending thoracic aorta and continues distally.

\section{STATISTICAL ANALYSIS}

Mean (SD) values are given. Linear regression analysis was performed and correlation coefficients ( $r$ ) and regression equations are given for comparison of aortic diameters measured by computed tomography and transoesophageal echocardiography.

\section{Results}

Four patients had type 1 aortic dissection, five had type II, and twelve had type III. Sixteen patients had hypertension and two had Marfan syndrome; in three patients the aetiology of dissection was unknown. There was aortic regurgitation in all patients with type I dissection and in four of five patients with type II dissection. Table 1 shows the results of transthoracic and transoesophageal echocardiography, computed tomography, and angiography, and the findings at operation and necropsy. Transoesophageal echocardiography detected dissection in all patients in whom it was shown by alternative techniques. Table 2 gives the diameters of the different parts of the aorta measured by transoesophageal echocardiography and computed tomography. Figure 4 shows a typical example of aortic dissection type $I$ in which there was an intimal flap within the ascending aorta, the aortic arch, and the descending aorta. In one young woman (patient 3 ) an entry tear $2 \mathrm{~cm}$ distal to the aortic valve was demonstrated by transoesophageal echocardiography and emergency operation was performed without further diagnostic procedures. In other woman (patient 4) operation was done after additional coronary angiography which demonstrated a stenosis in the distal part of the left anterior

Table 1 Clinical data and diagnostic results of 21 patients with aortic dissection

\begin{tabular}{|c|c|c|c|c|c|c|c|c|c|}
\hline Case & Age/sex & $\begin{array}{l}\text { Type of } \\
\text { dissection }\end{array}$ & $A I$ & TOE & $T T E$ & $C T$ & Angiography & Surgery & Necropsy \\
\hline $\begin{array}{l}1 \\
2 \\
3 \\
4\end{array}$ & $\begin{array}{l}28 \mathrm{M} \\
69 \mathrm{~F} \\
36 \mathrm{~F} \\
68 \mathrm{~F}\end{array}$ & $\begin{array}{l}\text { I } \\
\text { I } \\
\text { I } \\
\text { I }\end{array}$ & $\begin{array}{l}+ \\
+ \\
+ \\
+\end{array}$ & $\begin{array}{l}+ \\
+ \\
+ \\
+ \\
\text { (thrombus, SEC) }\end{array}$ & $\begin{array}{l}- \\
+ \\
+ \\
+\end{array}$ & $\begin{array}{l}- \\
+ \\
0 \\
0\end{array}$ & $\begin{array}{l}\overline{0} \\
\mathbf{0} \\
+\end{array}$ & $\begin{array}{l}+ \\
+ \\
+ \\
+\end{array}$ & $\begin{array}{l}\mathbf{0} \\
0 \\
0 \\
0\end{array}$ \\
\hline $\begin{array}{l}5 \\
6 \\
7\end{array}$ & $\begin{array}{l}30 \mathrm{~F} \\
77 \mathrm{~F} \\
71 \mathrm{~F}\end{array}$ & $\begin{array}{l}\text { II } \\
\text { II } \\
\text { II }\end{array}$ & $\begin{array}{l}+ \\
+ \\
+\end{array}$ & $\begin{array}{l}+ \\
+ \\
+ \\
\text { (thrombus) }\end{array}$ & $\begin{array}{l}\overrightarrow{+} \\
+ \\
+\end{array}$ & $\frac{0}{0}$ & $\overline{0}$ & $\begin{array}{l}+ \\
0 \\
0\end{array}$ & $\begin{array}{l}0 \\
0 \\
+\end{array}$ \\
\hline $\begin{array}{r}8 \\
9 \\
10\end{array}$ & $\begin{array}{l}36 \mathrm{~F} \\
55 \mathrm{~F} \\
52 \mathrm{M}\end{array}$ & $\begin{array}{l}\text { II } \\
\text { II } \\
\text { III }\end{array}$ & $\begin{array}{l}+ \\
- \\
-\end{array}$ & $\begin{array}{l}+ \\
+ \\
+ \\
\text { (thrombus, SEC) }\end{array}$ & $\begin{array}{l}- \\
-\end{array}$ & $\begin{array}{l}- \\
+(\text { MRT }) \\
+ \\
\text { (thrombus) }\end{array}$ & $\begin{array}{l}+ \\
+ \\
+\end{array}$ & $\begin{array}{l}0 \\
+ \\
0\end{array}$ & $\begin{array}{l}0 \\
0 \\
0\end{array}$ \\
\hline $\begin{array}{l}11 \\
12\end{array}$ & $\begin{array}{l}72 \mathrm{M} \\
64 \mathrm{~F}\end{array}$ & $\begin{array}{l}\text { III } \\
\text { III }\end{array}$ & $\overline{-}$ & $\begin{array}{l}+ \\
+ \\
\text { (thrombus, SEC) }\end{array}$ & $\begin{array}{l}+ \\
\text { (thrombus) }\end{array}$ & $\stackrel{+}{0}$ & $\begin{array}{l}0 \\
+\end{array}$ & $\begin{array}{l}\mathbf{0} \\
\mathbf{0}\end{array}$ & $\begin{array}{l}+ \\
+\end{array}$ \\
\hline 13 & $69 \mathrm{M}$ & III & - & $\stackrel{+}{\text { (thrombus, SEC) }}$ & - & + & + & 0 & 0 \\
\hline 14 & $76 \mathrm{M}$ & III & - & $\begin{array}{l}+ \\
\text { (thrombus, SEC) }\end{array}$ & - & $\stackrel{+}{\text { (thrombus) }}$ & 0 & 0 & 0 \\
\hline 15 & $71 \mathrm{M}$ & III & - & $\stackrel{+}{(\text { SEC })}$ & - & $\begin{array}{l}+ \\
\text { (thrombus) }\end{array}$ & 0 & 0 & 0 \\
\hline 16 & $66 \mathrm{~F}$ & III & - & $\begin{array}{l}+ \\
\text { (thrombus, SEC) }\end{array}$ & - & 0 & $\stackrel{+}{\text { (thrombus) }}$ & + & 0 \\
\hline 17 & $64 \mathrm{~F}$ & III & + & $\begin{array}{l}+ \\
\text { (thrombus, SEC) }\end{array}$ & - & (thrombus) & + & 0 & 0 \\
\hline 18 & $79 \mathrm{~F}$ & III & - & $\begin{array}{l}+ \\
\text { (thrombus, SEC) }\end{array}$ & - & 0 & + & 0 & 0 \\
\hline 19 & $63 \mathrm{M}$ & III & - & $\stackrel{+}{\text { (thrombus) }}$ & - & + & + & + & 0 \\
\hline 20 & $45 M$ & III & - & $\begin{array}{l}+ \\
\text { (thrombus) }\end{array}$ & - & $\stackrel{+}{\text { (thrombus) }}$ & - & 0 & 0 \\
\hline 21 & $72 \mathrm{M}$ & III & - & $\begin{array}{l}+ \\
\text { (thrombus) }\end{array}$ & - & $\begin{array}{l}+ \\
\text { (thrombus) }\end{array}$ & $\mathbf{0}$ & 0 & 0 \\
\hline
\end{tabular}

AI, aortic insufficiency; + , confirmed; - , no diagnosis by transthoracic and transoesophageal echocardiography (TTE/TOE), computed tomography (CT), aortic angiography (angio), surgery, or necropsy; 0, no data; SEC, spontaneous echocardiographic contrast; MRT, magnetic resonance tomography. 
Table 2 Transoesophageal echocardiographic (TOE) and computed tomographic (CT) diameters (D) of the ascending aorta, aortic arch, and descending aorta

\begin{tabular}{|c|c|c|c|c|c|c|c|}
\hline \multirow[b]{2}{*}{ Case } & \multirow[b]{2}{*}{$\begin{array}{l}\text { Type of } \\
\text { dissection }\end{array}$} & \multicolumn{6}{|c|}{ Aortic diameter ( $\mathrm{mm}$ ) } \\
\hline & & $\begin{array}{l}\text { Ascending aorta } \\
\text { TOE }\end{array}$ & $C T$ & $\begin{array}{l}\text { Aortic arch } \\
\text { TOE }\end{array}$ & $C T$ & $\begin{array}{l}\text { Descending aorta } \\
T O E\end{array}$ & $\vec{a}$ \\
\hline $\begin{array}{r}1 \\
2 \\
3 \\
4 \\
5 \\
6 \\
7 \\
8 \\
9 \\
10 \\
11 \\
12 \\
13 \\
14 \\
15 \\
16 \\
17 \\
18 \\
19 \\
20 \\
21 \\
\text { Mean (SD) } \\
\\
\text { Normal values }\end{array}$ & $\begin{array}{l}\text { I } \\
\text { I } \\
\text { I } \\
\text { I } \\
\text { II } \\
\text { II } \\
\text { II } \\
\text { II } \\
\text { II } \\
\text { III } \\
\text { III } \\
\text { III } \\
\text { III } \\
\text { III } \\
\text { III } \\
\text { III } \\
\text { III } \\
\text { III } \\
\text { III } \\
\text { III } \\
\text { III }\end{array}$ & $\begin{array}{l}63 \\
45 \\
37 \\
38 \\
61 \\
68 \\
55 \\
45 \\
50 \\
35 \\
45 \\
35 \\
36 \\
35 \\
35 \\
40 \\
64 \\
34 \\
44 \\
36 \\
35 \\
45(11) \\
D_{\text {CT }}=0 \cdot 85 D_{\text {TE }} \\
\mathrm{r}=0 \cdot 88 \\
<35 \mathrm{~mm}\end{array}$ & $\begin{array}{l}47 \\
50 \\
\overline{-} \\
\overline{70} \\
\frac{52}{52} \\
\frac{35}{50} \\
\frac{33}{32} \\
\frac{3}{61} \\
\frac{61}{46} \\
36 \\
35 \\
46(12) \\
\end{array}$ & $\begin{array}{l}26 \\
33 \\
25 \\
33 \\
28 \\
42 \\
33 \\
32 \\
30 \\
33 \\
45 \\
33 \\
33 \\
35 \\
32 \\
70 \\
40 \\
28 \\
50 \\
33 \\
30 \\
35(10) \\
\mathrm{D}_{\mathrm{ct}}=1.0 \mathrm{I} \\
\mathrm{r}=0.93 \\
<30 \mathrm{~mm}\end{array}$ & $\begin{array}{l}30 \\
36 \\
= \\
\frac{-}{46} \\
\frac{30}{30} \\
\frac{33}{50} \\
\frac{55}{35} \\
\frac{33}{40} \\
\frac{48}{34} \\
28 \\
37(7) \\
\text { E }+0.57\end{array}$ & $\begin{array}{l}25 \\
34 \\
27 \\
35 \\
25 \\
48 \\
28 \\
25 \\
22 \\
45 \\
35 \\
58 \\
38 \\
60 \\
35 \\
32 \\
54 \\
30 \\
57 \\
36 \\
38 \\
37(12) \\
\mathrm{D}_{\text {CT }}=1 \cdot 1 \mathrm{D}_{\text {TEE }} \\
\mathrm{r}=0.96 \\
<25 \mathrm{~mm}\end{array}$ & $\begin{array}{l}30 \\
\frac{38}{-} \\
\frac{54}{32} \\
\frac{32}{50} \\
\frac{40}{45} \\
\frac{75}{5} \\
\frac{58}{61} \\
39 \\
35 \\
46(14) \\
+0 \cdot 45 \\
\end{array}$ \\
\hline
\end{tabular}



Fig 4 Typical example of a type I dissection (patient 2) showing the intimal flap ( $\downarrow$ ) in the ascending aorta, the aortic arch, and the descending aorta. $L A$, left atrium; $L V$, left ventricle. 


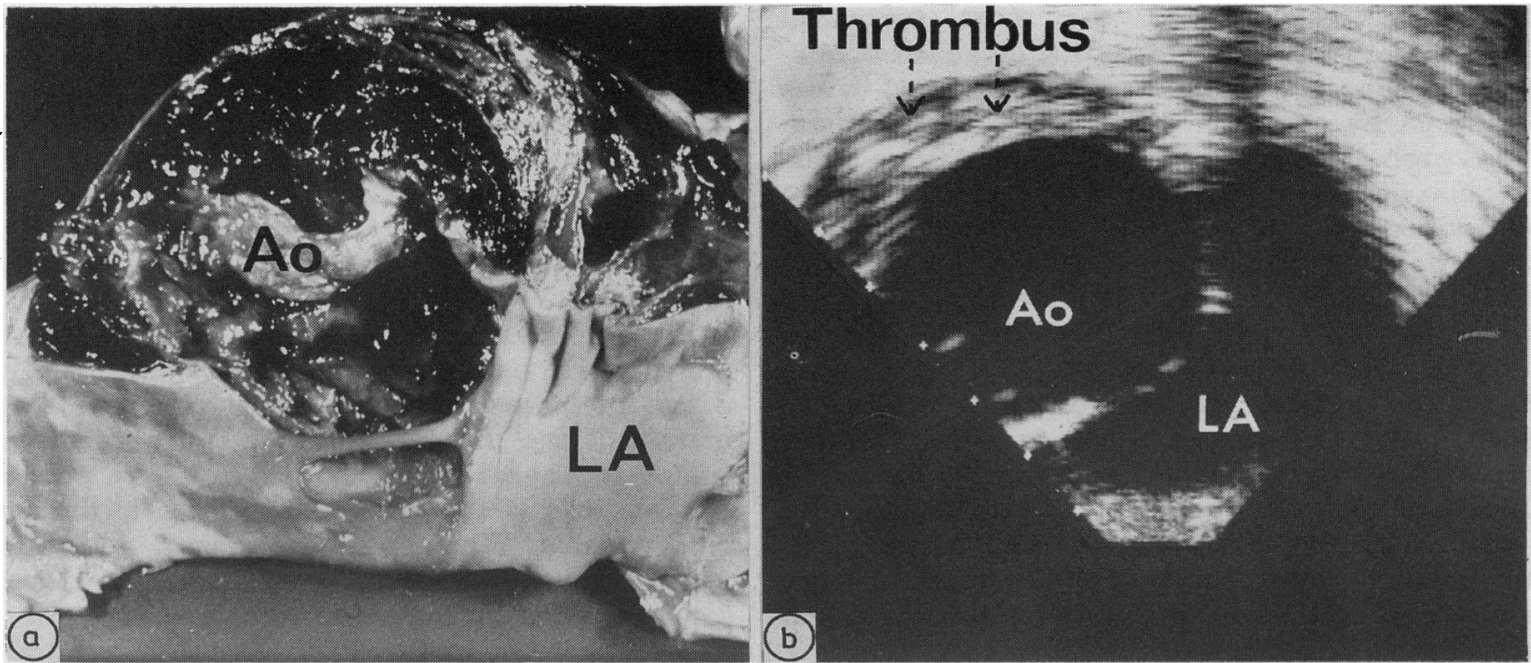

Fig 5 Section (a) and (b) cross sectional echocardiographic image of type II dissection with mural thrombus formation within the false lumen. To assist comparison the echocardiographic image has been turned upside down. Ao, aorta; $L A$, left atrium.

descending coronary artery. Transoesophageal echocardiography demonstrated the entry tear of the dissection in this case too.

A type II dissection was found by transoesophageal echocardiography in five patients, and an intimal flap showing movement parallel to the aortic wall was clearly demonstrated within the ascending part of the aorta in all five. The aorta was dilated in all five cases. Aortography was positive in only two of four of these patients. Diagnosis was confirmed at operation in two patients and by necropsy in another patient (fig 5 ). In this last patient the false lumen was filled with a thrombus, which explains the negative result at aortography.

A type III dissection was seen in 12 patients by transoesophageal echocardiography (fig 6). Computed tomography was positive in eight of nine of these patients. Aortography was performed in eight patients and was positive in seven. In eight of the 12 patients 'spontaneous echocardiographic contrast was seen within the aorta. There were circulating flow patterns and thrombus formation in that part of the aorta in which the spontaneous echocardiographic contrast was most obvious (fig 6). The starting point of the aortic dissection could be demonstrated in all 12 patients. In two patients with type III dissection the intimal entry tear could also be visualised.

\section{Discussion}

In up to $18 \%$ of patients aortic dissection may be missed at chest $x$ ray or may cause non-specific signs that do not distinguish the abnormality from aneurysmal dilatation or tortuosity and elongation of the aorta without dissection. ${ }^{15}$ Thus reliable noninvasive techniques are needed for immediate and accurate diagnosis in seriously ill patients with chest pain. ${ }^{16}$ Computed tomography and echocardio-

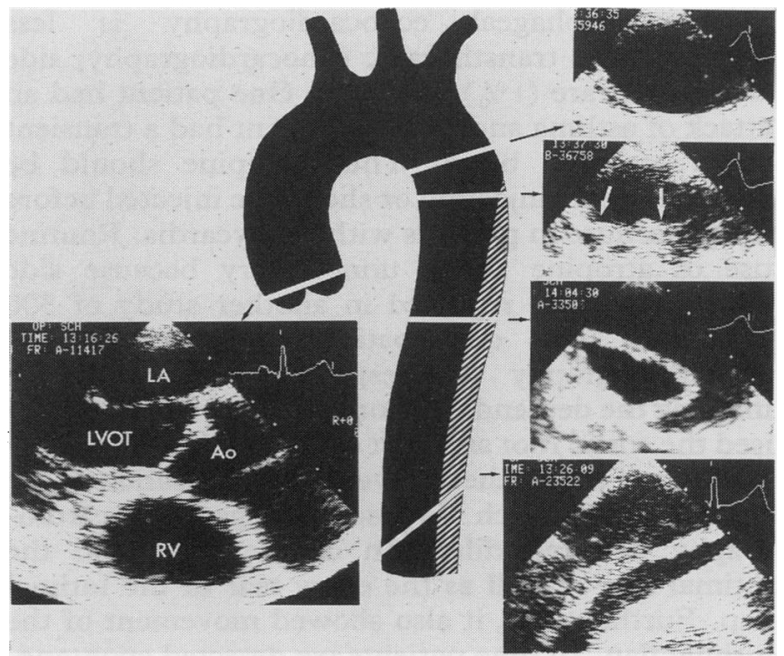

Fig 6 Transoesophageal echocardiogram showing type III aortic dissection and spontaneous echocardiographic contrast within the false lumen. Mural thrombus formation was seen in the part with the densest spontaneous echocardiographic contrast ( $\downarrow)$. LA, left atrium; LVOT, left ventricle outflow tract; $R V$, right ventricle; Ao, aorta. 
graphy are regarded as the most successful approaches. The first report of the diagnosis of aortic dissection by computed tomography ${ }^{17}$ was confirmed by others. ${ }^{1819}$ Detection of an intimal flap is probably the most specific sign. After a bolus injection of contrast medium true and false lumens were visualised in about $50 \%$ of patients in whom the aortic diameter was increased..$^{20-24}$ We had similar success with type I and II dissection. Type III dissection was successfully detected in $90 \%$ of patients. The strong movement of the intimal flap during the cardiac cycle may explain the negative results. The scanning time of $4 \mathrm{~s}$ for computed tomography cannot give a sharp image of the membrane in all patients.

$M$ mode echocardiography can detect enlargement of the aortic root, widening of the anterior or posterior aortic wall, and the presence of intimal flaps. ${ }^{1-325-28}$ Some workers have used scanning from multiple anatomical sites to image the whole of the thoracic aorta by cross sectional echocardiography ${ }^{529}$ and to distinguish the type and extent of dissection. ${ }^{29-32}$ Detection of distal dissection of the thoracic aorta was difficult. ${ }^{829}$ It was successful in only about $70 \%$ of cases. ${ }^{4}$ In our series diagnosis of type I and type II dissection was significantly more accurate than that of type III dissection. Transoesophageal echocardiography has eliminated some of these difficulties. ${ }^{33-36}$ Chest wall configuration, small intercostal space, obesity, pulmonary emphysema, and mechanical respiration limit the diagnositic value of transthoracic echocardiography.

Transoesophageal echocardiography is less pleasant than transthoracic echocardiography; side effects are rare $(1 \%)$, however. One patient had an attack of asthma and another patient had a transient atrioventricular block. Thus atropine should be ready for rapid injection or should be injected before the procedure in patients with bradycardia. Routine use of atropine seems unnecessary because side effects were not reported in another study of $\mathbf{3 0 0}$ patients. ${ }^{36}$ In our patients transoesophageal echocardiography was especially successful for imaging the descending thoracic aorta; it also visualised the aortic root and part of the aortic arch. Interposition of the trachea prevented visualisation of the complete aortic arch. Transoesophageal echocardiography detected dilatation of the aorta and the intimal flap as well as the entry tear of the intimal flap. Furthermore, it also showed movement of the intimal flap. In nine patients we detected spontaneous echocardiographic contrast within the false lumen; this finding has been reported by others. ${ }^{37} 38$ This was probably because reduced blood flow had caused aggregation of platelets and erythrocytes. ${ }^{39}$

There was a good correlation between the diameters of all parts of the aorta measured by transoesophageal echocardiography and by computed tomography; though the diameters measured by transoesophageal echocardiography were smaller than those measured by computed tomography. The scanning time required for collection of computed tomographic images $(4 \mathrm{~s})$ means that movement of the aorta is included and the aortic diameter is overestimated.

Further studies are needed to evaluate whether non-invasive techniques can replace aortography ${ }^{36}$ when, as in two of our patients, complete examination of the thoracic aorta by transthoracic and transoesophageal echocardiography is possible. Angiography could perhaps be limited to the coronary arteries. When transoesophageal echocardiography is not available the descending thoracic aorta can be studied by computed tomography.

Though acute aortic dissection of types I and II require prompt operation, ${ }^{40-44}$ there is little or no evidence that patients with chronic asymptomatic dissection need elective operation. ${ }^{16}$ There is controversy about whether acute type III dissection should be treated surgically or medically. ${ }^{16}$ In chronic type III dissection the indications for surgical intervention are restricted and conservative. ${ }^{164344}$ Thus after diagnosis of type III dissection by echocardiography no further diagnostic procedures are necessary in symptom free patients.

In our experience transoesophageal echocardiography complements transthoracic echocardiography, particularly for imaging the distal thoracic aorta. Intimal flaps and dilatation of the aorta caused by a dissection could be demonstrated by this method. Transoesophageal echocardiography seems to be better than computed tomography for demonstrating an intimal flap. Early diagnosis and prompt treatment should improve the prognosis in patients with aortic dissection. ${ }^{15}$

This study was supported by the Robert Müller Stiftung.

\section{References}

1 Nanda NC, Gramiak R, Shah PH. Diagnosis of aortic root dissection by echocardiography. Circulation 1973;48:506-13.

2 Krueger SK, Starke H, Forker AD, Eliot RS. Echocardiographic mimics of aortic root dissection. Chest 1975;67:441-4.

3 Hirschfeld DS, Rodriguez HJ, Schiller NB. Duplication of aortic wall seen by echocardiography. $\mathrm{Br}$ Heart $\mathrm{J}$ 1976;38:943-50.

4 Iliceto S, Ettorre G, Francioso G, Antonelli G, Biasco G, Rizzon P. Diagnosis of aneurysm of the thoracic aorta. Comparison between two noninvasive techniques: twodimensional echocardiography and computed tomography. Eur Heart J 1984;5:545-55.

5 Schweizer P, Erbel R, Lambertz H, Effert S. Two-dimensional 
suprasternal echocardiography in dissection of the thoracic aorta. In: Rijsterburgh H, ed. Echocardiology. The Hague: M Nijhoff, 1981:55-60.

6 Kasper W, Meinertz T, Kersting F, Lang K, Just H. Diagnosis of dissecting aortic aneurysm with suprasternal echocardiography. Am J Cardiol 1978;42:291-4.

7 Mintz GS, Kotler MN, Segal BL, Parry WR. Two dimensional echocardiographic recognition of the descending thoracic aorta. Am J Cardiol 1979;44:232-8.

8 Bubenheimer P, Schmuziger M, Roskamp H. Ein-und zweidimensionale Echographie bei Aneurysmen und Dissektionen der Aorta. Herz 1980;5:226-40.

9 Hanrath P, Kremer P, Langenstein BA, Matsumoto M, Bleifeld W. Transösophageale Echokardiographie. Ein neues Verfahren zur dynamischen Ventrikelfunktionsanalyse. Dtsch Med Wochenschr 1981;156:523-5.

10 Schlüter M, Kremer P, Hanrath P. Transoesophageal twodimensional echocardiography in the diagnosis of cor triatriatum in the adult. J Am Coll Cardiol 1983;2:1011-5.

11 Schlüter M, Kremer P, Hanrath P. Transesophageal twodimensional echocardiographic feature of flail mitral leaflet secondary to ruptured chordae tendineae. Am Heart J 1984;108:609-10.

12 Kremer $P$, Hanrath $P$, Langenstein BA, Matsumoto $M$, Tams $C$, Bleifeld $W$. The evaluation of left ventricular function at rest and during exercise by transoesophageal echocardiography in aortic insufficiency [Abstract]. Am J Cardiol 1981;47:412.

13 Börner N, Erbel R, Braun B, Henkel B, Meyer J, Rumpelt J. Diagnosis of aortic dissection by transoesophageal echocardiography. Am J Cardiol 1984;54:1157-8.

14 DeBakey ME, Cooley DA, Creech O Jr. Surgical considerations of dissecting aneurysm of the aorta. Ann Surg 1955; 142:586-612.

15 Earnest F, Muhm Jr, Sheedy PF. Roentgenographic findings in thoracic aortic dissection. Mayo Clin Proc 1979;54:43-50.

16 Doroghazi RM, Slater EE. Aortic dissection. New York: McGraw-Hill, 1983:133-64.

17 Harris RD, Usselman JA, Vint VC, Warmath MA. Computerized tomographic diagnosis of aneurysms of the thoracic aorta. J Comput Assist Tomogr 1979;3:81-91.

18 Sanders JH, Malave S, Niemann HL, Moran JM, Roberts AJ, Michaelis LL. Thoracic aortic imaging without angiography. Arch Surg 1979;114:1326-9.

19 Suchato C, Pekanan P, Singjaroen T, Sereerat P. Indication of dissecting aortic aneurysm on noncontrast computed tomography. J Comput Assist Tomogr 1980;4:115-6.

20 Heiberg E, Wolverson M, Sundaram M, Conners J, Susman N. CT findings in thoracic aortic dissection. Am J Roentgenol 1981;136:13-7.

21 Lardé D, Bellor C, Vasile N, Frija J, Ferrané J. Computed tomography in dissection of the thoracic aorta. Radiology 1980;136:147-51.

22 Godwin JD, Herfkens RL, Skiöldebrand CG, Federle MP, Lipton MJ. Evaluation of dissection and aneurysms of the thoracic aorta by conventional and dynamic CT scanning. Radiology 1980;136:125-33.

23 Gross SC, Barr I, Eyler WR, Khaja F, Goldstein S. Computed tomography in dissection of the thoracic aorta. Radiology 1980;136:135-41.

24 Moncada R, Churchill R, Reynes C, et al. Diagnosis of dissecting aortic aneurysm by computed tomography. Lancet $1981 ; \mathbf{i}: 238-41$. 
25 Egan TJ, Niemann HL, Hermann RJ, Malave SR, Sanders JH. Computed tomography in the diagnosis of aortic aneurysm, dissection or traumatic injury. Radiology 1980;136:141-6.

26. Moothart RW, Spangler RD, Blount SG. Echocardiography in aortic root dissection and dilatation. $A m$ J Cardiol 1975;36:11-6.

27 Krueger SK, Wilson CS, Weaver WR, Reese HE, Cavdill CC, Rourke T. Aortic root dissection: echocardiographic demonstration of torn intimal flap. JCU 1976;4:35-9.

28 Nicholson WJ, Cobbs BW. Echocardiographic oscillating flap in aortic root dissecting aneurysm. Chest 1976;70:305-7.

29 Victor MF, Mintz GS, Kotler MN, Wilson AR, Segal BL. Two-dimensional echocardiographic diagnosis of aortic dissection. Am J Cardiol 1981;48:1155-9.

30 Roudant R, Billès MA, Gateau P, Besse P, Dallocchio M. Twodimensional echocardiography in the diagnosis of aortic dissection in 41 patients [Abstract]. Circulation 1981;64 (suppl IV):314.

31 Nakamura K, Suzuki S, Satomi G, et al. Two-dimensional echocardiographic and RI angiographic features of aneurysm of the ascending aorta in patients with annuloaortic ectasia. $J$ Cardiogr 1981;11:239-52.

32 Bubenheimer $P$. Fortschritte in der Diagnose der Aortendissektion durch TM-und 2D-Echographie. Cardiology 1981;68 (suppl 1):66-74.

33 Hanrath P, Schlüter M, Langenstein BA, et al. Detection of ostium secundum atrial defects by transoesophageal crosssectional echocardiography. Br Heart J 1983;49:350-8.

34 Schlüter M, Langerstein BA, Polster J, et al. Transoesophageal cross-sectional echocardiography with a phased array transducer system. Technique and initial clinical results. $\mathrm{Br}$ Heart $J$ 1982;48:67-72.

35 . Schlüter $\mathbf{M}$; Langenstein BA, Hanrath $\mathbf{P}$, Kremer $\mathbf{P}$, Bleifeld W. Assessment of transesophageal pulsed Doppler echocardiography in the detection of mitral regurgitation. Circulation 1982;66:787-89.

36 Schlüter M, Hinrich A, Tier W, et al. Transoesophageal twodimensional echocardiography: comparison of ultrasonic and anatomic sections. Am J Cardiol 1984;53:1173-8.

37 Panidis JP, Kotler MN, Rintz GS, Ross J. Intracavitary echoes in the aortic arch in type III aortic dissection. Am J Cardiol 1984;54:1159-60.

38 Stern H, Erbel R, Börner N, Schreiner G, Meyer J. Spontaner Echokontrast, registriert mittels transösophagealer Echokardiographie bei Aortendissektion Typ III. Z Kardiol 1985;74:480-1.

39 Mikell FL, Asinger RW, Elsperger J, Anderson WR, Hodges $M$. Regional stasis of blood in the dysfunctional left ventricle: echocardiographic detection and differentiation from early thrombosis. Circulation 1982;66:775-83.

40 Earnest F IV, Muhm JR, Sheedy PF II. Roentgenographic findings in the thoracic aortic dissection. Mayo Clin Proc 1979;54:43-50.

41 Dalen JE, Alpert JS, Cohn LH, Black H, Collins JJ. Dissection of thoracic aorta. Medical or surgical therapy? Am J Cardiol 1974;34:803-8.

42 Kirklin JK, Kirklin JW. Invited commentary (to reference 32). World J Surg 1980;4:578-9.

43 Miller DC, Stinson EB, Shumway NE. Realistic expectations of surgical treatment of aortic dissections: the Stanford experience. World J Surg 1980;4:571-8.

44 Bergan JJ, Yao JST. Aneurysms. Diagnosis and treatment. New York: Grune and Stratton, 1982:105-18. 